\title{
Congenital absence of a part of the fallopian tube: a case report
}

\section{Mukta Agarwal*, Hemali H. Sinha, Anamika}

Department of Obstetrics and Gynaecology, AIIMS, Patna, Bihar, India

Received: 25 October 2016

Accepted: 23 November 2016

\author{
*Correspondence: \\ Dr. Mukta Agarwal, \\ E-mail: agarwal_mukta2006@yahoo.co.in
}

Copyright: () the author(s), publisher and licensee Medip Academy. This is an open-access article distributed under the terms of the Creative Commons Attribution Non-Commercial License, which permits unrestricted non-commercial use, distribution, and reproduction in any medium, provided the original work is properly cited.

\begin{abstract}
Congenital malformations of female genital tract are frequently seen in Gynaecological clinics, incidence being upto $5-6 \%$ in cases of infertility. Most of these anomalies are related to uterus and vagina, abnormalities related to ovaries and fallopian tubes are of rare occurrence and the exact incidence of these anomalies are not known, only a few incidental case reports are available in literature. Here, we present a rare case report of absent mid- tubal segment of fallopian tube in a patient of infertility.
\end{abstract}

Keywords: Congenital, Fallopian Tube, Mullerian anomalies, Torsion

\section{INTRODUCTION}

Mullarian anomalies are not uncommon to be encountered in gynaecology clinics, and the reported incidence is $0.1-0.5 \%$ in general and up to $6 \%$ in patients with infertility. ${ }^{1-3}$ Most common developmental malformations to be encountered are uterine followed by vaginal and cervical anomalies. Congenital anomalies of ovaries and fallopian tubes are rare to be seen in clinical practice. Partial or complete absence of fallopian tube is of very rare occurrence. Though, true incidence of this condition is not known but till now very few cases have been reported in literature. Here we present a rare case of partial absence of fallopian tube, which was diagnosed incidentally during diagnostic laparoscopy.

\section{CASE REPORT}

Mrs. X, 32 years old female, presented to the Gynaecology Outpatient department of a tertiary care centre of Eastern India as a case of primary infertility. Patient was married for eight years, staying regularly with the husband. Previous menstrual cycles were regular and nothing significant was revealed in past and family history. There was no history of surgery in the past.
General and Gynaecological examination was within normal limits. Investigations revealed normal husband's semen analysis, negative tuberculosis work-up (endometrial biopsy for TB-PCR was negative), S. TSH, Prolactin and anti-mullarian hormones were within normal limits. Though, her tubal testing was not done in the past, but she had received six cycles of ovulation induction outside, so she was taken for diagnostic laparoscopy and hysteroscopy.

Per-operatively, on hysteroscopy, uterine cavity was found to be normal, bilateral ostia were deep seated and eddy currents were present.

On laparoscopy, uterus was of normal size and shape. On left side, less than one cm stump was seen at cornual end followed by absent mid-tubal segment (about $2 \mathrm{~cm}$ in isthmic portion) followed by normal infundibulum and fimbrial end and the two portions were connected by a fold of mesosalpinx. There was a mid-tubal constriction on right side. Bilateral ovaries were normal and dye test was negative on both sides. Option of tubal reconstruction versus In-vitro fertilization (IVF) was given to the patient party and they decided to go for IVF. Post-operative period was uneventful. 


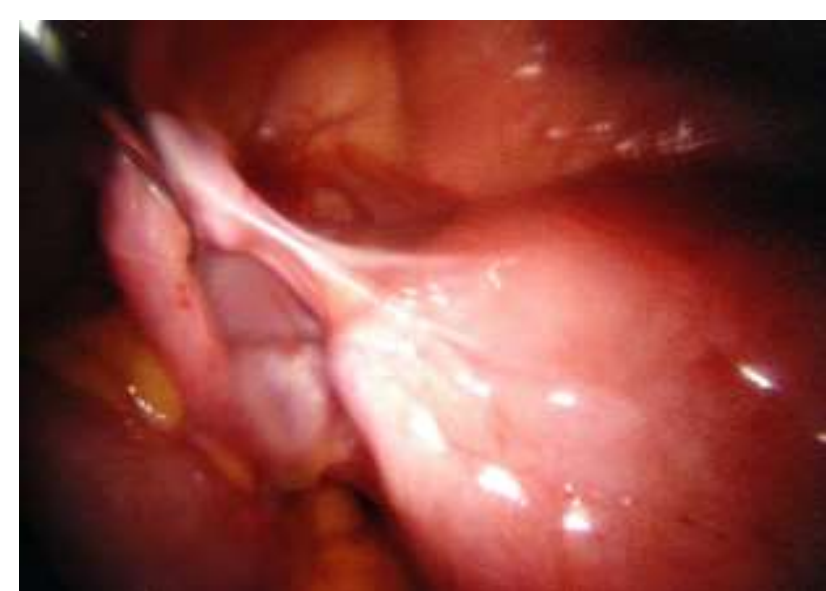

Figure 1: Laparoscopic view showing absence of part of Fallopian tube.

\section{DISCUSSION}

Anatomical abnormality of fallopian tube is of very rare occurrence, which mainly includes accessory ostia, multiple lumina, duplication, complete absence or partial atresia or segmental deletion of different regions of the tube. ${ }^{4-6}$ These are usually asymptomatic and diagnosed incidentally on laparoscopy for some unrelated indication. Anomalies of ovaries and fallopian tube are proposed to have two etiopathogenesis the first is an asymptomatic torsion of one or both adnexa during adult life or childhood, or even in the fetal stage..$^{7-8}$ The second cause may be that the absence is congenital owing either to a defect in the development of the entire Mullerian and mesonephric systems on one side or to a defect localized to the region of the genital ridge and the caudal part of the Mullerian duct.

Currently, we are using American Fertility Society (AFS) Classification to classify mullarian anomalies, but this classification does not include adenaxal malformation. On reviewing literature, we could find another new classification- The VCUAM classification, which also include tubal and ovarian malformations. ${ }^{9}$ According to this classification; our case belongs to class- A1a i.e. unilateral tubal malformation, ovary normal.

Nawroth et al reported 18 patients with partial atresia of the fallopian tubes in a comprehensive survey of the literature. ${ }^{10}$ Ukuyu et al reported four cases of congenital unilateral tubal and ovarian abnormalities. ${ }^{11}$ Apart from these; few other isolated rare case reports are also available in the literature. ${ }^{12-19}$

For most of the cases reported to date, the true etiologies of partial absence of the fallopian tube remain unclear. If there are other anomalies of the genital tract or the urinary system, the etiology is likely to be congenital. Absence of other anomalies suggests torsion as the cause, especially if the uterus and the other fallopian tube are normal.

\section{CONCLUSION}

Absence of a part or whole of the fallopian tube is very rare to be seen. It could either be congenital or secondary to asymptomatic torsion followed by auto- amputation or resorption, possible consequence of which could be subfertility. These cases are usually diagnosed incidentally on laparoscopy for some other reason. Though it is difficult to comment upon, but in absence of other abnormality, the likely cause of the absence of a part of fallopian tube in our case could be torsion of adenexa in the past, though we could not elicit history of any episode of severe pain abdomen in the past.

\section{Funding: No funding sources \\ Conflict of interest: None declared \\ Ethical approval: Not required}

\section{REFERENCES}

1. Raga F, Bauset C, Remohi J, Bonilla-Musoles F, Simon C, Pellicer A. Reproductive impact of congenital müllerian anomalies. Hum Reprod. 1997;12:2277-81.

2. Byrne J, Nussbaum-Blask A, Taylor WS, Rubin A, Hill M, O’Donnell R, et al. Prevalence of müllerian duct anomalies detected at ultrasound. Am J Med Genet. 2000;94:9-12.

3. Marten K, Vosshenrich R, Funke M, Obenauer S, Baum F, Grabbe E. MRI in the evaluation of müllerian duct anomalies. Clin Imaging. 2003;27:346-50.

4. Beyth Y, Kopolovic J. Accessory tubes, a possible contributing factor in fertility. Fertile Sterile. 1982;38:382-3.

5. Daw E. Duplication of uterine tube. Obstet Gynecol. 1973;42:137-8.

6. Eustace DL. Congenital absence of fallopian tube and ovary. Eur J Obstet Gynecol Reprod Biol. 1992;46:157-9.

7. Paternoster DM, Costantini W, Uglietti A, Vasile C, Bocconi L. Congenital or torsion-induced absence of fallopian tubes. Two case reports. Minerva Ginecol. 1998;50(5):191-4.

8. Dresler S. Antenatal torsion of a normal ovary and fallopian tube. Am J Dis Child. 1977;131:236.

9. Oppelt P, Renner SP. The VCUAM (Vagina Cervix Uterus Adnex-associated Malformation) Classification: a new classificaon for genital malformations. Fertility and Sterility. 2005;84(5):1493-7.

10. Nawroth F, Nugent W, Ludwig M. Congenital partial atresia of fallopian tube. Reprod Biomed Online. 2006;12:205-8.

11. Uckuyu A, Emel E. Unilateral congenital ovarian and partial tubal absence: report of four cases with review of literature. Fertil Steril. 2009;91:936.e5-8.

12. Lavanya R, Urala MS. Segmental absence of fallopian tube- a rare anomaly. Int J Gynecol Obstet. 1994;47:175-6. 
13. Dahan MH, Burney R, Lathi R.congenital interruption of the ampullary portion of fallopian tube. Fertil Steril. 2006;85:1820-1.

14. Cheung VY, congenital atresia of the fallopian tube. J Obstet Gynaecol. 2008;30:11-2.

15. Suh BY, Kalan MJ. Septate uterus with left fallopian tube hypoplasia and ipsilateral ovarian agenesis. J Assist Reprod Genet. 2008;25:567-9.

16. Pednekar R, Parulekar SV. Unilateral Segmental Absence of Fallopian Tube. JPGO. 2015;6(3). Available from: http://www.jpgo.org/2016/06/ unilateral-segmental-absence-of.html.

17. Hiroyuki Y. A case of congenital unilateral partial absence of fallopian tube. Fukushima J Med Sci. 2010;56(1).
18. Elkington N, Rahman R. Unexplained unilateral absence of fallopian tube and ovary. The International Journal of Gynecology and Obstetrics. 2008; 11 .

19. Mehul S, Shweta G. unexplained unilateral absence of fallopian tube and ovary - A rare occurrence. J South Asian Feder Menopause Society. 2014;2(1):46-7.

\section{Cite this article as: Agarwal M, Sinha HH,} Anamika. Congenital absence of a part of the fallopian tube: a case report. Int J Reprod Contracept Obstet Gynecol 2017;6:320-2. 